bién la belleza de la actitud. En estas historias-la de Sarmiento contada en prosa pindárica por Lugones; la de González Prada escrita con más fino don de intimidad por Luis Alberto Sánchez-se ve siempre la apostura de un titán luchando contra los geniecillos peludos y venenosos de su medio vernáculo. A veces-como en uno de los más conmovedores capítulos escritos por Luis Alberto Sánchez-, cae sobre el luchador una obscura hora de soledad en que solo le restan la sonrisa y comprensión de sacrificio de una mujer. Pero cuando el caudillo, uno de estos caudillos que en nuestra historia americana se cruzan en el camino del intelectual y están acostumbrados a hacerle su amanuense, panegirista o sofista de ocasión y remacharle por tanto, una cadena de servidumbre, quiere como el caudillo Piérola sobre González Prada, lograr su renunciamiento, el intelectual yergue en desesperado combate contra las cosas, toda la dimensión de su entereza. Historias edificantes de ayer, de todos los días, que nos placen más que ese vano y retorcido juego de caligramas en que otros escritores de América dejaron escaparse su hora.- M A R I A O P I C ó N S A L A S.

\title{
GRÔNICA DE ESPEGTẢGULOS
}

\section{El Teatro Real.-Berta Singerman}

HUENIO d'Ors decía, hace algunos años, a los muchachos 14 de la Residencia de Estudiantes:

Belleza no quiere decir ornamento, sino armonía, 'adecuación delicada de la cosa a su destino.

A un tiempo, en Francia, otra voz concordaba con la del filósofo de Cataluña; Le Corbusier formulaba su famoso principio estético:

Una casa es una máquina para vivir.

En ambas afirmaciones, que componen un solo postulado, descansa el principio de actualidad en las artes, que no equivale a una antojadiza orientación del deseo de originalidad, sino que traduce la idiosincrasia de una época.

El practicismo, las necesidades del confort y las tendencias deportivas de las costumbres modernas han creado un estado de ánimo incompatible con el barroquismo. La vida ha adquirido hoy día cierta allure que repudia la inocuidad del arabesco.

Por lo que se refiere a la arquitectura, los nuevos materiales 
establecen, además, imposiciones que es menester tomar en cuenta. Las construcciones han de realizarse en consonancia con las posibilidades estéticas del cemento armado, sin esforzarse por sobrepasarlas, para no tener que recurrir al postizo. El adorno es anacrónico como la profusa adjetivación lo es en un libro. Correspondiendo a la tendencia objetiva de la literatura, las artes plásticas sólo han de utilizar los elementos esenciales para interpretar el espíritu de la generación actual.

Todo esto parecen ignorarlo los arquitectos que han levantado en el centro de nuestra ciudad el edificio destinado al Teatro Real.

Examinemos su fachada. Columnas salomónicas. ¿Con qué objeto? Para sostener un mojinete liviano, por otra parte innecesario. Ventanas de segundo piso protegidas, de ladrones y asaltantes probablemente, por gruesas rejas de hierro. Firulentes y rúbricas de mal gusto en todas las cornisas y balcones.

Luego, en el interior, un salón con envigado postizo. Sobredorados e incrustaciones de mosaico por todos los rincones. Los grandes planos interrumpidos por arcos y columnitas, que simulan ventanas, sin ser más que hoyos feos e innecesarios en la muralla.

Lo peor de todo se encuentra en la sala de proyecciones. Junto al telón, pórticos, artificiosas construcciones pobladas de farolillos y recargadas de balcones sevillanos. $\mathrm{Y}$ como si esto fuera poco, detrás de ello se encuentran frescos de brocha gorda que hacen de fondo, dando la impresión de un decorado de zarzuela o del desgraciado paraninfo de la Universidad de Chile, que van a fundirse con el inevitable cielo azul.

Necesario es reconocer la comodidad de las instalaciones, la amplitud con que se han calculado los asientos, los pasillos de distribución y las puertas de salida; el sistema de refrigeración y calefacción es inmejorable, como asimismo nos parece un buen acuerdo la instalación de una plataforma movible para la orquesta.

Todo esto no hace más que agravar la culpa de los arquitectos y decoradores. Con base tan excelente y disponiendo de un mandatario que no se ha detenido en gastos, pudieron realizar una magnífica sala de espectáculos con todo género de comodidades, decorándola sobriamente, sin recurrir a ese amontonamiento de chirimbolos con que sólo han logrado épater les bourgeois.

Gracias a la iniciativa de Berta Singerman. hemos tenido oportunidad de conocer algunas piezas de teatro moderno, 
presentadas en adecuada forma. Durante la breve temporada realizada en el Teatro de la Comedia por el conjunto de Teatro de Cámara, presidido por la gentil declamadora de otros días, pudimos apreciar debidamente algunas producciones de Rosso de San Seccondo, Pirandello, Guitry, Jean Cocteau, etc.

Nada pudiéramos decir que no fuera en elogio de la organizadora y los componentes de esta compañía. La voz maravillosa de la Singerman, rica en matices, de tonalidades agradables, rozaba el ánimo de los expectadores, como una caricia que escalofría. La emoción puesta por esta actriz en cada uno de sus papeles se comunicaba por este medio al auditorio, especialmente en La Voz Humana de Cocteau. Caviglia se nos reveló un consumado primer actor en diversas caracterizaciones singularmente en Pantalón. En cuanto a Ilde Pirovano, sin desconocer que tiene méritos, debemos hacer notar que no se sitúa, a juicio nuestro, en idéntico plano. Tiene figura atrayente, pero está siempre fuera de situación; su voz no es agradable y su juego escénico carece por completo de personalidad. Sería una buena primera actriz para la Compañía Serrador, pero está fuera de lugar en el Teatro de Cámara.

La acción de los artistas estaba realzada por magníficos decorados y trajes diseñados por Urvantzof, de tendencia muy moderna, de un buen gusto impecable.

En sí mismo, el género presentado por la Singerman representa un regreso al teatro antiguo, a la cortina de fondo, lisa, obscura, sobre la cual se perfila el actor. En otros términos, se obtienen de este modo los efectos puramente teatrales y se pone a prueba la calidad de las obras.

El público no favoreció el espectáculo. Esto no nos parece extraño. Acostumbrado como está a las truculencias de los autores nacionales y a las caricaturas de nuestros actorés, carece de la disciplina necesaria para apreciar y aplaudir una pieza o un conjunto de calidad. De paso anotaremos la observación, que nos proponemos desarrollar en otra oportunidad, de que carece de aptitudes para percibir lo grotesco; en los instantes de mayor intensidad dramática, cuando una frase irónica establece los contrastes de la situación y subraya el matiz emocionante, nuestro público ríe, como con un chiste de Frontaura.

Sin embargo, podemos decir que se ha dado el primer paso hacia la educación de la masa que concurre a los teatros; que se le han mostrado las posibilidades del arte teatral y su nueva orientación. Y esto debemos agradecerlo cordialmente a Berta Singerman que, para lograrlo, ha sacrificado el éxito pecuniario de su primera temporada en Santiago.-A L F A. 